\title{
Producciones culturales para la infancia mexicana: los juguetes (1950-1960)
}

\section{Susana Sosenski*}

IIH-UNAM

Este artículo analiza la relación entre la infancia mexicana de mediados de siglo xx con el mundo del consumo en México, en específico con los juguetes. A partir de la revisión de publicidad en la prensa mexicana y de las recomendaciones de varias guías de cuidado infantil se muestran cuatro aspectos clave para entender los discursos que circularon alrededor de los juguetes para los niños: por un lado el juguete, como proveedor de felicidad y alegría infantil; el plástico como el material que redefinió los usos y la importancia de los juguetes para los nińos; los discursos de diversos especialistas en torno a los juguetes bélicos; y la utilización del juguete como transmisor de discursos de género.

(Consumo, infancia, juguetes, posguerra, publicidad)

Jim me enseñó su colección de plumas atómicas (los bolígrafos apestaban, derramaban tinta viscosa; eran la novedad absoluta aquel año en que por última vez usábamos tintero, manguillo, secante), los juguetes que el Señor le compró en Estados Unidos: cañón que disparaba cohetes de salva, cazabombardero de propulsión a chorro, soldados con lanzallamas, tanques de cuerda, ametralladoras de plástico (apenas comenzaban los plásticos), tren eléctrico Lionel, radio portátil. No llevo nada de esto a la escuela porque nadie tiene juguetes así en México. No, claro, los niños de la Segunda Guerra mundial no tuvimos juguetes. Todo fue producción militar. ${ }^{1}$

* Agradezco a Mónica Mendoza su colaboración en el proceso de investigación de este artículo así como las observaciones y sugerencias de Elena Jackson, Norma Ramos y los dictaminadores anónimos de este artículo.

${ }^{1}$ José Emilio Pacheco, Las batallas en el desierto, México, Era, 1999, 28. 
¿Qué relación tiene la historia de los juguetes con la historia social y cultural de México? Los juguetes son producciones culturales, ventanas a través de las cuales es posible vislumbrar tensiones, cambios y permanencias entre tradición y modernidad, clases sociales, géneros e incluso entre la opinión pública. A principios del siglo xx, Walter Benjamin definió al juguete como un bien cultural; en ese sentido, los juguetes no pueden ser vistos de manera separada a la nación y clase de la que forman parte ${ }^{2}$ " "están condicionados por la cultura económica, y sobre todo técnica, de las colectividades”. ${ }^{3}$ El juguete es también un objeto social y su complejidad radica en que "pone en movimiento una tecnología, un sistema de producción que se inserta en redes económicas, y todo un conjunto de conductas donde el imaginario juega gran parte". ${ }^{4}$ Llama entonces la atención que los historiadores mexicanos hayan ignorado "la historia del juguete y [que] sólo los psicólogos, los folcloristas y los etnólogos se [hayan interesado] en el juego del niño". 5 Es importante ver a los juguetes en una dimensión amplia, como instrumentos educativos y recreativos a los que niños y adultos les otorgan un conjunto de significados, usos y apropiaciones, como transmisores de valores socioculturales de una generación a otra, como reproductores de diferencias de clase y de género así como emisores de discursos hacia la infancia. Sobre todo en un momento en el que como señaló Gilles Lipovetsky, el orden económico del mundo occidental se rigió "según los principios de la seducción, lo efímero, la diferenciación de los mercados", es decir, las estrategias utilizadas por los empresarios fueron segmentar a las poblaciones por edades y por factores socioculturales. ${ }^{6}$

${ }^{2}$ Walter Benjamin, "The Cultural History of Toys", [1928], en Walter Benjamin, Selected Writings, vol. 2, 1927-1934, Cambridge, Belknap Press of Harvard University Press, 1999, 116.

${ }^{3}$ Walter Benjamin, Escritos: la literatura infantil, los niños y los jóvenes, Buenos Aires, Nueva Visión, 1989, 93. En esta cita Benjamin se refiere al libro de Karl Gröber, Juguetes infantiles de tiempos remotos, publicado en Alemania en 1928.

${ }^{4}$ Michel Manson, "La historia del juguete: un ámbito inexplorado en la historia de la educación (historiografía y problemática)", en María Esther Aguirre Lora, Rostros históricos de la educación. Miradas, estilos, recuerdos, México, Centro de Estudios Sobre la Universidad, Fondo de Cultura Económica, 2001, 211.

${ }^{5}$ Michael Manson, "La historia...”, p. 210.

${ }^{6}$ Gilles Lipovetsky, La felicidad paradójica, Barcelona, Anagrama, 2010, 30. 
En la década de 1950, México vivió un notable crecimiento demográfico y de urbanización que favoreció el ascenso de las clases medias. Éstas se colocaron como uno de los sectores con mayor capacidad para adquirir bienes de consumo. El modelo de sustitución de importaciones adoptado como una estrategia para el desarrollo interno y las medidas proteccionistas hacia la industria nacional dieron cierta estabilidad económica al país. Este clima de abundancia comenzó a conocerse como "el Milagro Mexicano". Sin embargo, este "milagro" no llegó a todos, grandes sectores de la población permanecieron en la pobreza. En 1958, por ejemplo, "la escolaridad media de la población era de menos de tres años y la posibilidad real de completar la educación media una excepción. A finales de los años cincuenta, el sistema escolar en México no había podido escapar a los desequilibrios del modelo de desarrollo". 7 El mercado mexicano no se cerró a los productos ni a la inversión extranjera, esencialmente estadounidense. En términos comerciales, es en estos años cuando el consumo aumentó de manera considerable, donde se observa de manera más notable la aparición de una sociedad de consumo de masas.

En las siguientes páginas me interesa -a partir de una investigación concentrada en fuentes primarias como guías de cuidado infantil y notas periodísticas- analizar algunas temáticas que se vincularon con los juguetes, una de las principales producciones culturales para el consumo infantil de los años cincuenta. Lo haré en torno a cuatro características que advierto relevantes y peculiares del contexto de mediados de siglo xx: la idea del juguete como proveedor de felicidad infantil, la importación y el plástico como valores intrínsecos al juguete, la preocupación de educadores, periodistas, pediatras y psicólogos por el uso de juguetes bélicos que inundaron el mercado en la década de 1950 y, por último, la reproducción de los roles de género que generaron los juguetes. Otro tema que corre a lo largo del artículo es la compleja relación entre México y Estados Unidos que puede vislumbrarse a partir del estudio de los juguetes.

${ }^{7}$ Soledad Loaeza, Clases medias y politica en México: la querella escolar, 1959-1963, México, El Colegio de México, 1988, 129. 
El análisis de las experiencias infantiles y de los usos que dieron los niños a los juguetes o las prácticas que estos objetos generaron, que algunos estudiosos han interpretado como "consumo cultural", tema esencial para comprender de manera más amplia de qué manera incidieron tanto las discusiones como los juguetes mismos en la construcción de identidades infantiles, quedarán como tarea pendiente para futuras investigaciones.

\section{Haga USTEd FELIZ A UN NIÑO}

Desde principios del siglo xx el niño se configuró como un sujeto de derecho. ${ }^{8}$ En ese contexto se diseminó una creencia generalizada de que los niños debían ser felices en todos los aspectos de su vida y que el Estado tenía una gran responsabilidad en ello. A nivel estatal no sólo se instauraron decenas de políticas para fomentar el bienestar de la infancia sino también se enfatizó como nunca la idea de que era necesario que los niños crecieran alegres.

A diferencia de otras épocas en las que la felicidad infantil se ligaba con "la salud, el honor y la fortuna”, en la década de 1950 la felicidad, la alegría y la diversión se relacionaron estrechamente con el mundo del consumo. ${ }^{9}$ La publicidad en la prensa apeló a los niños y a su felicidad desde el temprano siglo xx pero en los años cincuenta este tipo de anuncios se incrementaron. "El niño necesita aprender a ser feliz" aseguraba en 1952 el doctor Alfredo Ramos Espinosa, especialista en nutrición. ${ }^{10}$ Es decir, la felicidad no parecía ser un estado natural de la infancia ni mucho menos una casualidad, sino

\footnotetext{
${ }^{8}$ Me refiero a que desde el siglo xix se había discutido el tema del menor como sujeto de derecho pero fue en el siglo xx cuando se concretaron en el nivel internacional (y luego nacional) los derechos del niño, además se multiplicaron las políticas y los instrumentos jurídicos a favor de la protección a la infancia y el reconocimiento jurídico del niño. En 1924, la onu emitió la Declaración de los Derechos del Niño, luego en 1959 y en 1989. La Organización Internacional del Trabajo, por ejemplo, emitió sus primeras regulaciones para la infancia en 1919 .

${ }^{9}$ Pascal, en el siglo xviıI, señalaba que desde la infancia se le pedía a los hombres pensar en su felicidad. André Comte-Sponville, Jean Delumeau, Arlette Farge, La historia más bella de la felicidad, Barcelona, Anagrama, 2005, 10.

${ }^{10}$ Alfredo Ramos Espinosa, El cuidado del niño y la moderna psicología, puericultura pedagógica del niño mexicano, México, s.e., 1952, 107.
} 
una construcción, una forma de educación y un hábito en el que mucho tenían que ver los juegos, los buenos tratos de los padres, las diversiones o las adquisiciones de bienes materiales. Los publicistas, a través de múltiples campañas y técnicas de marketing, apelaron a los nińos y a sus padres para que a través de la compra de mercancías lograran llegar a tan ansiado estado. Mucha de la publicidad de la prensa de mediados de siglo enfocada a la venta no sólo de juguetes sino de automóviles, terrenos, comida, televisiones o refrigeradores giró en torno a la tópica de la felicidad. Los objetos materiales, parecían indicar los anuncios, acercaban a padres e hijos a través de estados emocionales que iban desde la diversión, la salud, hasta la felicidad. En ese sentido, la publicidad se sirvió de discursos médicos y pedagógicos para articular sus campañas. Un ejemplo de la articulación de estos discursos publicitarios con los de los especialistas sobre la infancia y el mundo médico y farmacéutico de la posguerra puede verse en el anuncio en el que las familias mexicanas eran representadas por una sonriente familia de clase media feliz gracias a las tabletas Anejista. Este anuncio se publicó primero en inglés en revistas estadounidenses tan prestigiosas como Life. Ahí el antihistamínico aparecía condecorado, garantizado por las "buenas amas de casa" y recomendado por la revista Reader's Digest y la Parents Magazine una de las primeras publicaciones en Estados Unidos en la que convergieron médicos, psicólogos y pedagogos en sugerir métodos, objetos y novedades para la crianza de de los nińos. ${ }^{11}$

Varios autores coinciden en que en el mundo occidental la década de los años cincuenta "la búsqueda incesante de felicidad como placer y bienestar no hizo más que agudizarse". ${ }^{12}$ Se ha sugerido que fue un momento en el que la sociedad "se moviliza alrededor del proyecto de conseguir una cotidianidad cómoda y fácil, que es sinónimo de felicidad". ${ }^{13}$ Si bien, este universo emocional compartido, con todas sus variantes, estuvo estrechamente vinculado con el consumo de masas, también obedeció a otros múltiples factores: a dife-

\footnotetext{
${ }^{11}$ Véase por ejemplo, Life, 25 de febrero de 1951, 4.

${ }^{12}$ Darrin M. McMahon, Una historia de la felicidad, México, Taurus, 2006, 458.

${ }^{13}$ Gilles Lipovetsky, La felicidad... p. 30.
} 
rencia de décadas previas se asistía a un momento en el que el mundo parecía haberse pacificado; la esperanza de vida se incrementaba rápidamente; el estado de bienestar parecía resolver demandas sociales en torno a salarios, educación, salud y trabajo; las enfermedades lograban curarse gracias a los avances tecnológicos, científicos y a las intensas campañas para erradicarlas; los transportes acercaban a las personas en tiempos más cortos. El mercado de consumo apoyado en estas circunstancias y en los medios masivos de comunicación se encargó de convencer que la felicidad y la alegría dependían en gran parte de la posibilidad de adquirir los deseos materiales y el confort a través del acto de comprar objetos.

En este contexto, los niños fueron convertidos en poderosos agentes de persuasión para la compra de diversos objetos de consumo, entre los que ocuparon un lugar predominante los juguetes. Las empresas destinaron tal vez más dinero que nunca a ejecutar decenas de estrategias mercadotécnicas (premios, afiliaciones a clubes, cercanía a personajes famosos como deportistas o actores, reproducción en miniatura de dibujos animados) para vender juguetes a los niños que pronto comenzaron a determinar en qué gastaban dinero sus padres.

Si la publicidad de juguetes aludió al hedonismo y buscó convencer a los adultos de que la felicidad, el crecimiento, la diversión o la educación infantil serían casi inalcanzables sin la compra de algún juguete, los discursos psicológicos y pediátricos compartieron en gran parte esta apreciación. De tal forma, parecía que los juguetes por sí mismos otorgaban alegría, enseñaban habilidades, acercaban a padres e hijos, mantenían a los niños ocupados, inspiraban actividad, desarrollaban la motricidad y el intelecto. Tener juguetes se convirtió implícitamente en un derecho de los niños. El médico Feliciano Sánchez Ríos, quien entre otros cargos había ocupado la jefatura de la oficina de Divulgación Higiénica de la Secretaría de Salubridad, la presidencia de la Sociedad Mexicana de Eugenesia y de la Asociación Mexicana de Puericultura y Nipiología, ${ }^{14}$ aseguraba

\footnotetext{
${ }^{14}$ Un término cuya correcta acepción sería nepiología, que se refiere a la rama de la pediatría que se ocupa de las condiciones de salud de los lactantes.
} 
que "no se concibe a un niño sin juguetes", y que los niños necesitaban gran variedad porque no podían concentrarse con sólo uno de ellos. ${ }^{15}$

En la década de los años cincuenta proliferaron guías y manuales en torno al cuidado de los bebés y la educación de los niños dirigidos a padres y maestros. En México circularon traducciones de textos de pediatras y psicólogos estadounidenses, argentinos, españoles o austriacos, entre otros. Muchas de estas publicaciones no alcanzaron la difusión que hubieran deseado sus editores y desconocemos cuál fue el impacto real en los métodos de crianza y cuidados infantiles, pero en todo caso, lo que nos interesa aquí es subrayar las ideas y discursos que se difundieron en ese momento en torno a los juguetes. ${ }^{16}$

En tanto se consideraba que los niños "exponían" sus problemas jugando, los padres debían proporcionarles materiales para que sus juegos fueran creativos. ${ }^{17}$ Es interesante advertir que en un contexto de boom de producción industrial de juguetes y de mercadotecnia al respecto, las guías insistían a padres y a maestros para que elaboraran juguetes junto con sus hijos con materiales que existieran en los hogares. Se indicaba que no era necesario comprar juguetes caros. El célebre libro Tu hijo, del pediatra estadounidense Benjamín Spock vendido en México seńalaba: "algunos padres se lamentan a veces de no poder comprar a su hijo un complicado coche de pedales o una gigantesca casa de muńecas si se trata de una nińa. Pero a los niños no son los juguetes más caros los que más les interesan". ${ }^{18}$ Un libro del médico y psicoanalista austriaco Wilhelm Stekel, que se había

\footnotetext{
${ }^{15}$ Feliciano Sánchez Ríos, La puericultura en México, obra de texto de acuerdo con los programas vigentes de la materia, México, Publicaciones Puericultura, 1952, 541, 545.

${ }^{16}$ Un ejemplo de la apropiación que se hizo en México de textos de otros países fue el caso del libro de Feliciano Sánchez Ríos, La puericultura en México... publicada en 1952. En muchos de sus pasajes pueden encontrarse fragmentos literales que sin que su autor lo reconociera pertenecían al texto del médico español José Barón Fernández, que había publicado su libro Manual de Puericultura en 1941 y que había sido reeditado en México en 1950. Confrontar por ejemplo, José Barón Fernández, Manual de Puericultura, México, s.e., 1950, 161 y Feliciano Sánchez Ríos, La puericultura..., p. 540.

${ }^{17}$ Michel Mason, "La historia...”, p. 63.

${ }^{18}$ Benjamin Spock, Tu hijo, Madrid, Daimon, Biblioteca Práctica del Hogar, 1957, 264.
} 
publicado en México en 1940 y una década después era recomendado por la prensa de la época como una lectura "para la familia mexicana", ${ }^{19}$ relataba:

en las familias ricas, es usual llenar al nińo de regalos y darle juguetes que reproducen, en miniatura, el mundo de los adultos. La experiencia demuestra que es absolutamente inútil secundar así la imaginación de los niños. El niño rico tiene una muñeca parlante que dice "mamá" y cierra los ojos, tiene varios vestidos, lencería fina, un cochecito, una camita, etcétera. El nińo pobre toma un trozo de madera, un trozo de cualquier cosa multicolor y la imaginación hace el resto con una habilidad admirable. ${ }^{20}$

En 1945, Oficina del Niño de la Dirección Federal de Previsión Social de Estados Unidos publicó un texto titulado Your Child from One to Six. Al parecer quienes se encargaron de la traducción al español fueron los técnicos de Instituto Internacional Americano de Protección a la Infancia, un organismo que se había creado en Montevideo, Uruguay en 1927. ${ }^{21}$ Este texto, distribuido en América Latina, indicaba qué juguetes eran los apropiados para diversas edades infantiles y señalaba que: "muchos juguetes educativos, hechos en casa, cumplen la misma misión que los comprados, que son más caros" ${ }^{22}$ El libro de la psicoanalista estadounidense Florence Powdermaker, traducido al español en la Biblioteca de Cultura Pedagógica en Argentina y reseñado en México por Ángel Dotor, ${ }^{23}$ decía: "la felicidad de un niño no aumenta en proporción al número de juguetes que posee". ${ }^{24}$

${ }^{19}$ Véase "Los temas supremos. Psicología y pedagogía. Ciencias de la educación”, El Porvenir, 11 de septiembre de 1951, 3.

${ }^{20}$ Wilhelm Stekel, Cartas a una madre, Buenos Aires, Iman, 1959, 168.

${ }^{21}$ Información tomada de la página web worldcat.org

${ }^{22}$ Estados Unidos, Children's Bureau, El niño de uno a seis años, Washington, U.S. Govt. Print. Off, 1947, 101.

${ }^{23}$ Ángel Dotor, "Los temas supremos. Psicología y pedagogía. Ciencias de la educación”, El Porvenir, 11 de septiembre de 1951, 3.

${ }^{24}$ Florence Powdermarker y Louise Ireland Grimes, Cómo atender y cómo entender al niño, manual para padres y maestros, Buenos Aires, Kapeluz, 1954, 137. 
Estas discusiones en el ámbito de la pediatría y la psicología infantil no se encontraban tan lejos de las apreciaciones de algunos sectores de la opinión pública en México como probablemente sí lo estuvieron de los usos, apropiaciones y lecturas de la mayor parte de las familias mexicanas. En todo caso, como hemos señalado páginas atrás, son interesantes en la medida en que reflejan concepciones de infancia y de familia en la época. El médico y psicólogo Alfredo Ramos Espinosa, especialista en niños que había sido secretario de la Sociedad Mexicana de Geografía y Estadística. En su obra El cuidado del niño y la moderna psicología publicada en 1952 apuntaba:

los juguetes más sencillos, los que el niño puede colocar a su arbitrio para servir a sus designios, son los más queridos. No nos desencantemos cuando habiéndole comprado un juguete muy bonito para nuestro gusto es roto por el niño para ver que tienen por dentro o tal vez para simplificarlo despojándolo de su forma real. Lo importante no es comprar un juguete caro sino que divierta al niño, que pueda maltratarlo sin inconveniente y que sea querido por él. [...] Antes que pegarle por los costosos juguetes que rompe, procurémosle los más sencillos de los que pueda plenamente disfrutar. ${ }^{25}$

Florencio Escardó, neuropediatra argentino leído en México. ${ }^{26}$ señalaba al respecto: "muchos adultos creen que los nińos juegan con ellos, cuando en realidad lo que pasa es que ellos juegan con los niños; el arquetipo de esta situación es la del padre que compra a su hijo un complicado meccano o un lujoso tren eléctrico para divertirse todos los grandes de la casa, pero el chico no". ${ }^{27}$ La crítica al papel de los padres en los juegos infantiles e interacción con sus hijos era una constante, era una época en la que se exigía atender las necesidades particulares de los niños y brindarles objetos de acuerdo a sus necesidades específicas.

${ }^{25}$ Alfredo Ramos Espinosa, El cuidado del niño..., pp. 103, 106.

${ }^{26}$ Pedro Solís Quiroga, por ejemplo, citó sus trabajos en su artículo: "La neurosis, los trastornos emocionales y los problemas de conducta de los niños débiles mentales", Criminalia, 1 de junio de 1958, 388.

${ }^{27}$ Florencio Escardó, Anatomía de la familia, Buenos Aires, El Ateneo, 2a ed, 1952, 77. 
Pedagogos y psicólogos parecieron coincidir en que los niños no requerían los juguetes más caros del mercado para su desarrollo motriz, intelectual o afectivo. Sin embargo, al mismo tiempo, eran tantas las recomendaciones para que los niños no se lastimaran, ensuciaran o enfermaran al jugar, que los juguetes industriales por lejos resultaban los más recomendables, tanto por su durabilidad, sus pinturas no tóxicas o la posibilidad de ser lavados. Así, el mundo del cuidado de la felicidad infantil en relación con los juguetes se cercaba alrededor de los sectores sociales que podían adquirir el juguete industrial. El médico guerrerense Alfonso Alarcón, que había mantenido estrecho contacto con prestigiados pediatras europeos, fue jefe de Higiene Infantil en la ciudad de México y, entre otros cargos y distinciones, miembro honorario de la Sociedad pediátrica de París, Cuba y Nueva York. ${ }^{28}$ Además de sus numerosos artículos en El Universal sobre temas de salud infantil, en 1940 publicó su libro El cuidado del niño: los cien mejores consejos que puede recibir una madre acerca de la salud de su niño pequeño, que para 1954, año de su muerte, se vendía en 10 pesos. ${ }^{29}$ En este texto advertía: "los juguetes para los niños pequeños deberán ser ligeros, irrompibles e insolubles [...] Los juguetes de celuloide son recomendables, a condición de que no se les acerque al fuego por que son inflamables" ${ }^{30}$ Es decir, los manuales oscilaban entre la invitación a fabricar los propios juguetes, la insistencia en que los padres debían cumplir con los deseos de sus hijos, y la invitación a comprar juguetes fabricados. Para la década de 1960 este discurso comenzó a ser más abierto. Los pediatras estadounidenses Harry Robert Litchfield y Leon Haskins Dembo en su Guía para el cuidado de su hijo indicaban: "hay que tratar de brindarle el tipo de juguete con el cual sueña. Es verdad que pronto se cansará de él. Pero esto es típico en la mayoría de los niños [...] El hecho de que un niño tenga muy pocos juguetes puede ser un factor que cause descontento, inquietud e irritabilidad". ${ }^{31}$

${ }^{28}$ Diccionario Porrúa de historia, biografia y geografía de México, vol. 1, México, 1995, 84.

${ }^{29}$ Gaceta médica de México, 1 de enero de 1954, 33.

${ }^{30}$ Alfonso G. Alarcón, El cuidado del niño: los cien mejores consejos que puede recibir una madre acerca de la salud de su niño pequeño, México, Nipios, 1940, 139, 140.

${ }^{31}$ Harry Robert Litchfield y Leon Haskins Dembo, Guía para el cuidado de su hijo, Buenos Aires, Paidós, 1966, 271 [Primera edición en inglés: 1960]. 
Si los fabricantes y vendedores de juguetes retomaron las propuestas de los especialistas en cuidado infantil, no fue tanto para dejar a las familias y a los nińos a su libre albedrío sino para proveerles una gigantesca variedad de juguetes. A nadie en la industria le convenía que éstos se hicieran en casa con materiales reciclados. Ante una comunidad infantil mexicana muy heterogénea los fabricantes de juguetes debieron emplear modernas estrategias comerciales para llegar a los niños y sus padres y convertir al juguete en una mercancía clave del mundo del consumo familiar. No sólo se valieron de creativas y novedosas campańas publicitarias en la prensa, la radio y la televisión, sino de diversas estrategias comerciales. Algunas de esas estrategias fueron colocar los juguetes a la altura de los niños en las tiendas departamentales y jugueterías; promocionar afiliaciones a clubes infantiles en determinadas marcas de dulces y juguetes; usar a personajes famosos para promocionar; crear vitrinas que los nińos pudieran observar en su caminar por las calles o abrir espacios y pisos dedicados a la venta de juguetes. ${ }^{32}$

Los manuales de cuidado infantil, la publicidad en la prensa o los juguetes industriales hacían referencia a una población infantil de clase media y alta. Pero en un país con una población tan heterogénea hubo muy diversas formas de acceder a los juguetes. ¿Qué sucedía con los niños pobres que no tenían capacidad adquisitiva para comprar juguetes industriales? El Estado a través de sus dependencias, así como la iniciativa privada se encargaron de que los niños en situación de calle, los trabajadores o los huérfanos no se quedaran a la zaga en el mundo del consumo de juguetes industriales. La tradicional entrega de juguetes que sucedía en México desde principios del siglo xx continuó. Para los niños de los años cincuenta se organizaron centenares de "repartos" públicos que se anunciaban en la prensa. Estas fotografías y reportajes con frecuencia se concentraban en mostrar la actitud benevolente de mujeres y hombres adultos en relación con la infancia pobre.

${ }^{32}$ Véase Susana Sosenski, "El niño consumidor: una construcción publicitaria de mediados de siglo xx", en Ariadna Acevedo y Paula López Caballero, coords., Ciudadanos inesperados. Procesos de formación de la ciudadanía ayer y hoy, México, Departamento de Investigaciones Educativas, Cinvestav, El Colegio de México (en prensa). 
Una representación de la infancia excepcional en este periodo fue la de Nacho López, fotoperiodista mexicano formado en el cardenismo, que retrató con crudeza las condiciones de la infancia pobre en México evidenciando su postura crítica a los gobiernos priístas de los años cincuenta y su distanciamiento con otros fotoperiodistas de la época. En una de sus fotografías mostró a un niño pobre vestido con overol de mezclilla sosteniendo de la cola a un ratón, cual si fuera un juguete, lo miran cuatro niños sonrientes. Con esta foto López mostraba las miserables condiciones de los hijos de los pobres, también la creatividad que afloraba "por falta de juguetes de lujo", ${ }^{33}$ El fotógrafo mostraba, en opinión de John Mraz, que "la falta de juguetes era dolorosa, pero podía estimular la creatividad de los niños pobres y llevarlos a inventar sus propios juguetes", Cabe mencionar que los fotoensayos sobre niños pobres "en este periodo remarcaban la falta de juguetes, pero nunca consideraban los posibles efectos no nocivos, como la inspiración de crear los propios", 34 en ese sentido, las fotografías de López son testimonio no sólo de la multiplicidad de infancias sino también del acceso a los bienes culturales .

Los niños más pobres podían comprar en los mercados o acudir a las "ferias del juguete" en las que muchos de los "puesteros" eran los mismos artesanos que fabricaban los juguetes que vendían. En la ciudad de México, por ejemplo, estas ferias se ubicaban a un costado de la Estación de Buenavista, en los portales del Zócalo, el norte de la Alameda, el monumento a la Revolución, las calles de Comonfort, Naranjo, Romero de Terreros o los puestos semifijos en torno al Monumento a la Revolución. Ahí compraban también los niños de clase media que podían acudir a las tiendas departamentales, a jugueterías en el centro de la ciudad, en la Avenida de los Insurgentes e incluso en el Bosque de Chapultepec. En todos estos sitios los precios eran significativamente más bajos que en El Puerto de Liverpool, Sears, Palacio de Hierro o las jugueterías de prestigio.

${ }^{33}$ John Mraz, Nacho López y el fotoperiodismo mexicano en los años cincuenta, México, Océano, 1999, 110.

${ }^{34}$ John Mraz, Nacho López..., p. 101. 
De una forma u otra, en fechas ligadas a la infancia como el Día de Reyes (6 de enero), el Día del Niño (30 de abril) y la Nochebuena (24 y 25 de diciembre) la ciudad con sus vitrinas, las páginas de sus periódicos, los anuncios en radio y televisión, parecía llenarse de juguetes. En el mes de diciembre los periódicos relataban que

la actividad comercial de la Metrópoli gira en torno a los juguetes infantiles, en la mayoría de las calles del centro y aún en las barriadas. Desde las colonias más elegantes hasta las más humildes, el paseante encuentra las tiendas de juguetes y los puestos que se instalan en las márgenes de calles y avenidas. El transeúnte, al ir por unas y otras, tiene la impresión de que México es, en estos días, una ciudad consagrada a pensar solo en los niños. ${ }^{35}$

\section{DOS VALORES ESENCIALES: EL PLÁSTICO Y LA IMPORTACIÓN}

Entre las recomendaciones de la Dirección Federal de Previsión Social de los Estados Unidos, retomadas en México por la Oficina del Niño en 1958 se encontraba la siguiente:

El bebé quiere chupar y morder lo que tenga a su alcance. Por esta razón, todos sus juguetes deben ser de tal calidad que no ofrezcan peligro al ser llevados a la boca. Deben ser lavables y no tener puntas ni esquinas afiladas; serán de un tamaño que no puedan tragarse, y no tendrán tampoco cananitas o pitos que puedan ser tragados. Los juguetes de goma o los de hueso son excelentes. ${ }^{36}$

Si "el juego está fuertemente influenciado y definido por la cultura y el entorno social en el que se desenvuelve y los juguetes son un reflejo del mundo adulto", ${ }^{37}$ no es fortuito que algunas de las carac-

35 "México, ciudad consagrada a pensar sólo en los niños", El Universal, 23 de diciembre de 1953, 21.

${ }^{36}$ Katharine F. Lenroot, ¿Cómo debe cuidarse al niño en su primer año?, México, Novaro, 1958, 95.

${ }^{37}$ Cita del psicólogo alemán Erik Erikson en María del Carmen Martínez Reina y Manuel Vélez Cea, "Actitud en nińos y adultos sobre los estereotipos de género en juguetes infantiles”, Ciencia Ergo Sum 16, 2009, 138. 
terísticas que ofreciera el mercado de juguetes de mediados del siglo pasado, por ejemplo, fuera la idea de lo irrompible y lo duradero. El plástico se convirtió en un símbolo de la modernidad en una época en la que todo parecía perdurar poco o transformarse rápidamente. Este material desplazó a todos los demás en las estanterías de juguetes. Era más barato que la madera, el metal, el celuloide o el acero y, sin bordes cortantes, los juguetes de plástico parecían más seguros para los niños, además de que eran lavables. A sus virtudes se agregaba que resistían al "trato desconsiderado" y los "suplicios tremendos" a los que los sometían sus pequeños usuarios, pues "en diversos estudios y observaciones se ha visto que estos someten a sus juguetes a torturas que el cuerpo humano no sería capaz de resistir además de que se podían lavar y eran más ligeros".${ }^{38}$ En un fotorreportaje se mostraban las pruebas que los fabricantes hacían de "capacidad de resistencia” de los muñecos de plástico, al calor, a los azotes, las caídas, el aplastamiento o el hundimiento en agua, todas torturas en potencia que podían infringir los niños.

Las casas fueron llenándose de plástico y la avalancha de juguetes baratos hizo que paulatinamente desaparecieran otras tradiciones como los "sanatorios de muñecas" 39 que existían todavía a mediados de siglo en algunas ciudades. Ahora la palabra plástico vendía por sí misma. Se anunciaban "divertidas cunitas musicales con dos muñecos, todo de plástico", tractores de plástico, "con ruido del motor al caminar", carros controles, camiones de volteo, motos con sidecar, coches ambulancias de la cruz roja, tanques de guerra y hasta juegos de té todo "en fino plástico", "completamente en plástico", "con resistente plástico". Los anunciantes aseguraban que los bebés irrompibles de hule que lloraban y dormían, "le durarán eternidades a su hijita".

El novedoso plástico no sólo hizo que los juguetes fueran duraderos sino que pronto ocupó un lugar importante en el léxico infantil. A esto contribuyó la mercadotecnia. Los modernos juguetes para

\footnotetext{
38 "Y sin embargo se rompen. Los niños, bomba H para los juguetes", Mañana, 8 de mayo de 1954, 37.

${ }^{39}$ Antoniorrobles, "Casa de muñecas. Drama ibseniano", Mañana, 29 de julio de 1950,51 .
} 
niños no eliminaron a los tradicionales ni a los producidos por la imaginación infantil: una botella vacía a modo de torre, corcholatas simulando llantas de automóvil ni tampoco aquellos juguetes populares mexicanos que seguían vendiéndose en mercados o puestos ambulantes: boxeadores de madera, baleros, trompos, matatenas o muñecas de trapo.

A los juguetes de plástico se les sumó un valor adicional: el de la importación. Aun cuando en esos ańos el gobierno mexicano se empeñaba en difundir la idea de que "lo hecho en México está bien hecho" para animar a los habitantes a tener confianza en los productos mexicanos y fortalecer la economía nacional, además de proteger a la industria mexicana de la competencia extranjera, lo cierto era que la novedad era el plástico y si era importado, mejor. Así encontramos anuncios de "shooting galleries", "divertidísimos juegos de salón, metálicos, importados", violines importados, faros importados para bicicleta, claxon importados para bicicleta con pilas y que "suenan como los de los autos". Ante la marejada de productos importados, esencialmente desde Estados Unidos, se convirtió casi en una "obligación patriótica de cada mexicano" consumir lo hecho en México, es decir, "participar en la nueva cruzada industrial, unos invirtiendo en nuevas empresas, otros aportando técnicas y la mayoría, los consumidores, soportando la carga que significaba comprar productos nacionales de inferior calidad y a precios más elevados" ${ }^{40}$ Algunos comercios, como la fábrica de juguetes infantiles Pirámide, se sumaron a los afanes gubernamentales y anunciaban:

No se deje sorprender con vehículos importados aparatosos y burdas imitaciones a los del país, de dudosa calidad que le venden a precios estratosféricos, nuestros vehículos infantiles compiten ventajosamente con los mejores del mundo, por su fino acabado, gran resistencia y que vendemos a precios de verdadera oportunidad. ${ }^{41}$

${ }^{40}$ Ramón Eduardo Ruiz, México: 1920-1958: el reto de la pobreza y del analfabetismo, México, Fondo de Cultura Económica, 1977, 85.

${ }^{41}$ Anuncio en Excélsior, 19 de diciembre de 1954, 12 a. 
A mediados de los años cincuenta se aseguró que la importación de juguetes se había reducido gracias al desarrollo de la pequeña industria de la juguetería mexicana, al impulso del gobierno de Adolfo Ruiz Cortines y del jefe de Departamento del Distrito Federal, Ernesto Uruchurtu para la instalación de ferias populares. ${ }^{42} \mathrm{Sin}$ embargo, aun con la política de puertas cerradas a los productos del exterior, la importación de juguetes en México continuó. Incluso, algunos de los industriales más destacados en el campo de la juguetería de plástico, como los estadounidenses Paul Saunders y Stanley Cherwin, dueños de la compañía Saunders Tool \& Die y José Ciklik y Simon Snaider de Novedades Plásticas, S.A. instalaron sus fábricas en este país y consiguieron las patentes para moldear materiales plásticos. Patentes que pertenecían a la Sun Rubber Company, una de las principales empresas en el continente que se encargaba de fabricar muñecos, primero de vinil y trapo, luego de plástico. ${ }^{43}$

El tema de la importación de juguetes se ligó con el nacionalismo declarado por los regímenes mexicanos. Se creía que se estaban importando más que objetos, ideologías. Sobre todo cuando la población mexicana veía que el barbudo Santa Claus aparecía en cada esquina. Numerosos artículos, fotografías y caricaturas aparecieron en la prensa mexicana para criticar lo que se consideraba una "invasión" tanto de objetos como de sujetos:

Movimiento contra Santa Claus. Quince de los más importantes gerentes de los grandes comercios en México están efectuando reuniones secretas con el objeto de "boycotear" al popular viejecito de las barbas blancas y la casaca roja, Santa Claus. Como argumento principal sostienen el de que Santa es un invasor extranjero, pues en el México de principios de Siglo no era conocido ni siquiera de nombre, ya que los obsequios que los padres hacían a sus hijos coincidían siempre con la llegada de los Tres Reyes Magos, Gaspar, Melchor y Baltasar, no con la tra-

${ }^{42}$ Alejandro Campos Bravo, "Es indispensable luchar contra los juguetes bélicos", El Nacional, 2a sección, 2 de enero de 1954, 1.

43 "El mundo de los niños. Dos grandes empresas, Saunders Tool \& Die Co. y Novedades Plásticas, S.A. crean los más bellos juguetes para hacer feliz a la niñez", Mañana, 22 de marzo de 1952, 226-227. 
dicional Cena de Noche Buena, como ahora. Estudiando detenidamente sus ventas los comercios han notado que les favorecía más la distinción entre los regalos de Navidad y los del Día de Reyes, pues aquello abarcaba dos presupuestos (diciembre y enero), en tanto que con Santa Claus todo se junta. ${ }^{44}$

La prensa se encargó de publicar textos de articulistas que probaban que las costumbres estadounidenses que "pervertían" el alma del mexicano, no sólo hablaban del desplazamiento de los Tres Reyes Magos por el barbudo Santa Claus, o de la lucha entre el "simiesco" rock and roll contra el tradicional danzón, sino también proliferaron reportajes en los que el tema principal fue la venta de juguetes bélicos a la infancia mexicana. La paradoja era que al terminar de leer estos artículos los lectores daban vuelta a la página y se encontraban con anuncios de una plana en los que un sonriente Santa Claus invitaba a sus "pequeños amiguitos" a comprar pistolas, tanques y rifles de plástico importado.

\section{LOS NIÑOS JUEGAN A LA GUERRA}

Del plástico y la importación derivó un tercer tema que preocupó a los mexicanos en la relación del juguete con la infancia: los juguetes bélicos. Éstos no eran una novedad del siglo xx. En su estudio pionero, Philippe Aries describe cómo Luis XIII de Francia, siendo niño a principios del siglo XVII, jugaba con un cañón pequeño y hacía "pequeñas acciones militares con sus soldados". ${ }^{45}$ Los niños han jugado a la guerra desde épocas todavía más distantes. Sin embargo, a mediados del siglo xx el contexto bélico, los medios masivos de comunicación y las acciones para la protección a la infancia, le dieron a las discusiones públicas y a la venta de juguetes un cariz absolutamente distinto. Un periodista de El Nacional señalaba que:

44 “...Con Barrios Gómez”, Mañana, 29 de diciembre de 1951, 55.

${ }^{45}$ Philippe Ariès, El Niño y la vida familiar en el Antiguo Régimen, México, Taurus, $1998,95$. 
en el ambiente se respira una psicosis bélica creada por las grandes potencias mundiales que viven pensando en agredirse y en defenderse mutuamente. Se respira desde hace ya tiempo un aire cargado de amenazas de conflagración y ello produce una formidable impronta en el alma infantil. El niño, siguiendo el ejemplo de sus mayores, piensa también en la guerra. Lo cual se traduce en sus juegos. ${ }^{46}$

Desde finales de la Primera Guerra Mundial, los fabricantes de juguetes habían hecho cañones, rifles y centenares de cajas de coloridos soldaditos de plomo que parecían más listos para simular desfiles que batallas militares. El término de la Segunda Guerra, la Guerra de Corea y la Guerra Fría exacerbaron no sólo el clima bélico sino también la producción de juguetes con este tema. El poderío económico de Estados Unidos "estaba acompañado de una gran fuerza militar expresada por el dominio de la tecnología nuclear, la producción de armamentos, y el establecimiento de bases militares en todos los continentes". ${ }^{47}$ Los juguetes junto con otras producciones culturalea, como los cómics o las películas, reprodujeron el clima bélico internacional.

Lo ideal fuera que los gobiernos dejaran de pensar en la guerra, y dejando de pensar en ella, los periódicos dejarían de hablar de supuestos bélicos de defensa o agresión. La radio, la televisión y los demás medios de difusión no hablarían tampoco de ellos, en el ambiente dejaría de flotar la terrible guerra, la posición bélica desaparecería y los niños, ya sin esa influencia, se desenvolverían en un medio hostil a toda manifestación violenta de la fuerza. ${ }^{48}$

Una nota del New York Times en julio de 1957 afirmaba que los juguetes, como nunca antes, imitaban de manera realista la vida, "el

${ }^{46}$ Esteban Durán Rosado, "Valor educativo del juguete", El Nacional, 27 de agosto de 1957,3 .

${ }^{47}$ Blanca Torres, Historia de la Revolución Mexicana, 1940-1952. Hacia la utopía industrial, vol. 21, México, El Colegio de México, 1984, 8-9.

${ }^{48}$ Esteban Durán Rosado, "Valor educativo del juguete", El Nacional, 27 de agosto de 1957,3 . 
programa de defensa nacional y las armas nucleares más modernas han sido causa de más reproducciones en miniatura de equipo militar de las que juguetilandia ha visto en diez años". ${ }^{49}$ De tal forma, si en esta época continuó la venta de soldaditos, fueron ahora ya no de plomo sino de plástico y en actitud tan ofensiva que hasta incluían "su juego de enfermeras y camilleros" y "sus servicios de Cruz Roja”. Había también "granadas auténticas" que estallaban después de caer a veinte o treinta metros, dardos, escopetas, aviones, tanques, ametralladoras, submarinos y una gran variedad de rifles, escopetas y pistolas. ${ }^{50}$ Algunos cálculos estimaban que 60\% de los juguetes, que se vendían a los niños mexicanos, eran bélicos. ${ }^{51}$ Los juguetes entrenaban tanto para el futuro como para el mundo presente de los adultos, ${ }^{52}$ así que debían reflejar la última tecnología disponible. Si los adultos daban uso a los ferrocarriles, los submarinos, los barcos, los aviones o la energía nuclear, las representaciones en pequeño de estos medios daban a los niños la posibilidad, de al menos en su imaginación, identificarse e imitar a los adultos, además de ensayar "guerras de mentiras".

A la par del aumento de juguetes de carácter militar, se incrementaron las críticas pacifistas a estos productos. En el periodo de entreguerras, pedagogos y psicólogos comenzaron a atribuirle a los juguetes bélicos la capacidad de formar y desarrollar en los niños caracteres violentos e instintos agresivos. En tanto el espíritu bélico inundó los medios de comunicación, también lo hizo el espíritu pacifista. ${ }^{53}$ Se consideraba que las réplicas en miniatura de las má-

49 "Juguetes atómicos", Guión de acontecimientos nacionales e internacionales, 15 de agosto de 1957, 40 (Nota traducida del New York Times)

${ }^{50}$ Gary S. Cross, Kids' Stuff: Toys and the Changing World of American Childhood, Cambridge, Massachusets, Harvard University Press, 2001, 154.

51 "Los fabricantes de juguetes se aferran a manufacturar los de naturaleza bélica", El Nacional, 27 de diciembre de 1956, 13.

${ }^{52}$ Gary S. Cross, Kids'Stuff..., p. 50.

${ }^{53}$ Véase Eugenio Ortero Urtaza, "Jugar a soldados y educar para la paz. Un análisis en perspectiva histórica" y Andrés Payárico, "Una Pedagogía Lúdico-Pacifista de protección a la Infancia (una breve aproximación histórica)" en Coloquio de Historia de la Educación, Paulí Dávila Balsera y Luis María Naya, La infancia en la historia: espacios y representaciones, Donostia, Erein, 2005, 430-450. Agradezco estas referencias a Norma Ramos. 
quinas de guerra creaban en el niño "un carácter arrebatado", lo "impulsaban a la belicosidad" y constituían un "verdadero peligro". Algunos articulistas llegaron a plantear que era necesario ocultar a los niños el clima político mundial, "en forma tal que no sepan de la existencia de las guerras ni de los instrumentos bélicos". ${ }^{54}$ El escritor de cuentos infantiles Antonio Joaquín Robles, mejor conocido como Antoniorrobles dedicó decenas de páginas a criticar el juguete bélico, “Malditas las pistolas de juguete, que cultivan en el niño ese movimiento instintivo de acribillar a tiros a sus amiguitos desde una esquina cualquiera!" 55 Y agregaba: "el niño que ha disparado con sus pistolas, siquiera sea con la boca desde una esquina, lleva ese movimiento del dedo dentro del alma para toda la vida" ${ }^{56}$ A esto se sumaba el temor de que muchos juguetes parecían verdaderas armas y en manos de niños o adultos podían causar alguna desgracia. El reportero de El Nacional, Alejandro Campos Bravo, escribió: "en reiteradas ocasiones las notas rojas de los periódicos han entintado en sangre vidas y hogares, porque, los niños juegan con pistolas auténticas una vez que se han ensayado con armas de mentiras". ${ }^{57}$

En este contexto, el 13 de septiembre de 1953, un grupo de personas, encabezadas por el ingeniero Luis G. Franco y por Salvador de León, quienes llevaban "cerca de quince ańos" "lanzando iniciativas y realizando importantes trabajos en una vigorosa campaña contra el juguete bélico", fundaron la Asociación Nacional Pro-educación Antibélica. Franco, antiguo encargado de las campañas antialcohólicas de la época posrevolucionaria, era calificado ahora como el "apóstol" que llevaba una "cruzada" en contra del juguete bélico para la niñez. Esta idea tenía antecedentes en Estados Unidos. En el estado de Delaware se habían prohibido los juguetes de guerra y se había amenazado con sanciones económicas a los padres que

54 "Los fabricantes de juguetes se aferran a manufacturar los de naturaleza bélica", $E l$ Nacional, 27 de diciembre de 1956, 13.

${ }^{55}$ Antoniorrobles, "Confidencias de un Rey Mago", Mañana, 23 de diciembre de 1950, 40-41.

${ }^{56}$ Antoniorrobles, "Caballos, muñecas y pistolas", Jueves de Excélsior, 28 de mayo de 1959, 14.

${ }^{57}$ Alejandro Campos Bravo, "Es indispensable luchar contra los juguetes bélicos", El Nacional, 2a sección, 2 de enero de 1954, 1. 
infringieran la ley. ${ }^{58}$ Una vez que terminó la Segunda Guerra un tema pendiente fue la protección de la infancia en términos amplios. El Universal aplaudía la iniciativa de las

campańas mundiales para regenerar el buen gusto por el juguete, los ingleses primero y los americanos después, inventaron y perfeccionaron ese ingenioso artículo llamado mecano, colección de innumerables piezas destinadas a despertar la invención infantil y crear todo género de piezas mecánicas de uso común desde una carretilla hasta una grúa, desde un torno, hasta una pequeña fábrica. ${ }^{59}$

Aunque el secretario de educación pública, José Ángel Ceniceros, durante el desfile militar del 16 de septiembre había externado algunas ideas contra los juguetes bélicos desde el balcón de Palacio Nacional, ${ }^{60}$ algunos periodistas acusaban que las "prédicas" de Franco se habían "perdido en el desierto de los intereses creados" y que la industria del juguete en México se había fortalecido "con la ayuda de las autoridades" ${ }^{61}$ La prensa utilizó a la fotografía como un medio idóneo para mostrar a los lectores la relación entre la infancia y la guerra. También ahí se criticaba que pese al "clamor nacional, nadie se ha preocupado en dictar medidas proteccionistas para el juguete pacifista y volveremos a ver inundadas las jugueterías con todas las manifestaciones de una época absurda de violencia". ${ }^{62}$

La campaña pacifista de Franco se sumó a la que llevaba en la prensa Antoniorrobles y se concentró en fomentar "al máximo las ideas de paz en las nuevas generaciones" y crear conciencia de que

${ }^{58}$ Antonio Magańa Esquivel, "Juguetes de Guerra”, El Nacional, 10 de enero de 1957, 3; Laura de Pereda, "Proscribamos los juguetes bélicos", El Nacional, 5 de noviembre de 1953, 7 .

59 "Ante los juguetes bélicos que pervierten el alma de la niñez", El Universal, 1 sección, 8 de diciembre de 1952, 9.

${ }^{60}$ Laura de Pereda, "Proscribamos los juguetes bélicos", El Nacional, 5 de noviembre de 1953,7 .

${ }_{61}$ "Avante los juguetes bélicos que pervierten el alma de la niñez", El Universal, $1^{\text {a }}$ sección, 8 de diciembre de 1952, 9.

62 "Avante los juguetes bélicos que pervierten el alma de la niñez", El Universal, $1^{\mathrm{a}}$ sección, 8 de diciembre de 1952, 9. 
los juguetes bélicos causaban "daño a la infancia" por ello llamaba proscribirlos por completo. ${ }^{63}$ Franco señalaba que al manejar una ametralladora, un tanque o un cañón de juguete, el niño iba "preparando su mente para la guerra”. ${ }^{64}$ Este ingeniero hizo propaganda entre los fabricantes de juguetes para que no fabricaran ametralladoras, tanques o pistolas; recorrió ferias del juguete "por el bien de la paz mundial y de la propia humanidad", ${ }^{65}$ emplazó a funcionarios, maestros, periodistas, locutores, conferencistas, escritores y padres de familia, sin embargo, pese a todas estas acciones su campaña no tuvo éxito.

Los dueños de jugueterías se negaron a retirar los juguetes bélicos para evitar "pérdidas desastrosas". Comenzó a considerarse que ya había juguetes "pasados de moda”, construidos de metales ligeros, como unas "preciosas bailarinas de manufactura alemana" que observó un reportero en su visita a una juguetería y que ya nadie quería comprar "porque en concepto de los nińos actuales, eran "cosa estúpida". ${ }^{66}$ De tal forma, la prensa se movió en dos direcciones, por un lado, en publicar los insistentes razonamientos de algunos activistas antijuguetes bélicos, por otro, en difundir centenares de anuncios de juguetes de este tipo. En este caso, a diferencia de la promoción de la felicidad, el mercado fue más fuerte que médicos, maestros y psicólogos, por lo que padres e hijos continuaron comprando la representación en plástico de las modernas armas de la destrucción. Ante esta situación, el doctor Ramos Espinosa urgió a los padres: "no los enseñéis a jugar a matar. Enseñadlos a que podemos vivir con alegría sin matar a nadie. [...] No compréis para los niños pistolas ni rifles. Si ellos juegan a la guerra, que no sea porque nosotros lo enseñemos". ${ }^{67}$ $1955,2$.

63 "Ningún juguete bélico deberá darse a la niñez", El Nacional, 24 de diciembre de

${ }^{64}$ Alejandro Campos Bravo, "Es indispensable luchar contra los juguetes bélicos" en El Nacional, 2a sección, 2 de enero de 1954, 1.

${ }^{65}$ Alejandro Campos Bravo, "Es indispensable luchar contra los juguetes bélicos" en El Nacional, 2a sección, 2 de enero de 1954, 1.

66 "Ante los juguetes bélicos que pervierten el ama de la niñez", El Universal, 1ª sección, 8 de diciembre de 1952, 9.

${ }^{67}$ Alfredo Ramos Espinosa, El cuidado del niño... p. 102. 
El negocio de las armas de juguetes traspasó las diferencias sociales y las armas fueron vendidas tanto en sus versiones baratas como en las más caras. Sin embargo, algunos representantes de la opinión pública diferenciaron a públicos consumidores. Francisco Sayrols, editor de la popular revista infantil Paquin, así como el escritor Esteban Durán Rosado, culparon a los padres de promover en sus hijos "un estado anímico filobélico mediante el obsequio de juguetes de ese tipo". ${ }^{68}$ Mientras la prensa publicaba fotos de la rubia hija del secretario de hacienda Ramón Beteta con sus muñecas de cabellos también bermejos, mostrando que un buen padre era aquel que colmaba de juguetes a sus hijos, ${ }^{69}$ Sayrols victimizaba a los sectores populares acusándolos de no hacer sacrificios suficientes para comprar juguetes constructivos: "prefieren comprar una pistola barata y lo que es peor, un puñal de hule para entretenimiento de sus hijos. Y naturalmente con estos juguetes solamente pueden aprender a matar, herir y si se trata de defenderse será después de robar cuando son perseguidos por ficticios policías" ${ }^{70}$ La crítica de Sayrols acerca de la compra de pistolas baratas y puñales de hule era despectiva hacia las posibilidades económicas de los sectores populares pero también determinista, pues en su opinión, los juguetes bélicos baratos condicionaban a un futuro delincuencial. Sayrols no hablaba de los costosos aviones militares dirigidos por control remoto que se compraban para los niños de clase media y alta.

\section{REPROdUCCIONES MINIATURA PARA DEFINIR GÉNEROS}

A principios del siglo XvII, el Delfín jugaba con muñecas, con "un pequeño gabinete de Alemania”, que le habían regalado y con un "pequeño hidalgo muy bien vestido con cuello perfumado." A los siete ańos "todos se esforzaban en hacerle abandonar los juegos de la primera infancia, principalmente el de las muñecas”, indicándole

\footnotetext{
${ }^{68}$ Esteban Durán Rosado, "Valor educativo del juguete", El Nacional, 27 de agosto de 1957,3 .

${ }^{69}$ Mañana, 14 de enero de 1950, 14.

${ }^{70}$ Francisco Sayrols, "Editorial”, La familia, 15 de marzo de 1950, 4.
} 
que había "dejado de ser niño". ${ }^{11}$ Se le prohibió jugar con muñecas más por una cuestión de edad que de género. Philippe Ariès señala que en el siglo XVII "la muñeca no estaba reservada a las nińas. Los niños también jugaban con ella”. ${ }^{72}$

La construcción del género, la relación entre infancia, la cultura del consumo y la modernidad aparece de manera muy clara en el tema de los juguetes. Desde el siglo xIx existió una actitud de niños y padres de acumular juguetes; se entendía que las posesiones materiales indicaban el estatus del poseedor. A mediados del siglo xx hubo un esfuerzo importante de la industria del juguete para expandir sus mercados, de tal manera surgieron diversos bienes de consumo específicamente designados y vendidos para niños: ropa, juguetes, muebles, productos para el cuidado infantil. ${ }^{73}$

Los juguetes han sido utilizados por los adultos para definir identidades y diferenciaciones de la infancia basadas en la edad, el género, la clase social, incluso la raza. ${ }^{74}$ Es decir, los juguetes y su uso a través el juego vinculan estructuras más amplias como la relación entre los niños y el poder o entre los niños y la construcción de identidades. En la década de 1950, los juguetes delimitaron una vez más las fronteras entre el mundo adulto y el infantil, aunque en muchas ocasiones se pretendiera que a través de ellos los niños imitaran o reprodujeran los valores del mundo adulto en una especie de "sociedad a escala”. La modernidad, el confort, la rapidez y los roles de género aparecieron como trasfondo de los discursos publicitarios en torno a los juguetes. Los avances tecnológicos y la electrificación también se manifestaron en los juguetes. Así, los trenecitos de cuerda, "exactas reproducciones a escala de los más modernos ferrocarriles" eran ofrecidos no sólo como "simples juguetes" sino como incitadores de la imaginación y la felicidad hogareña. ${ }^{75}$ Autitos eléc-

${ }^{71}$ Philippe Ariès, El niño y la vida..., p. 97, 99.

${ }^{72}$ Philippe Ariès, El niño y la vida..., p. 104.

${ }^{73}$ Daniel Thomas Cook, The Commodification of Childhood: the Children's Clothing Industry and the Rise of the Child Consumer, Durham, Duke University Press, 2004, 2.

${ }^{74}$ Bernard Mergen, "Made, Bought, and Stolen: Toys and the Culture of Childhood" en Elliott West y Paula Evans Petrik, Small Worlds: Children \& Adolescents in America, 1850-1950, Lawrence, Kansas, University Press of Kansas, 1992, 86-89.

${ }^{75}$ Anuncios, El Universal, 1a sección, 18 de diciembre de 1951, 6. 
tricos Ford, también a escala, arrancaban, retrocedían o daban vuelta “iicon un solo control!! ¡Eléctrico!” Y para que los niños aprendieran a jugar y representar la vida consumista también se vendía un "supermercado metálico, atractivo y vistoso" con báscula y rollo de papel. ${ }^{76}$ Estas características hacían de los juguetes objetos novedosos y modernos.

Las estrategias comerciales insistieron en crear espacios específicos para el consumo infantil, utilizaron a los personajes ficticios más queridos de los niños, prometieron regalos y premios. Si bien, el fin último era la venta, los juguetes de las tiendas departamentales colaboraron en la construcción de los modelos de infancia en México. Uno de los discursos más reiterados para que los niños imitaran la vida adulta a través de los juguetes tuvo que ver con el género. Es importante resaltar que el reforzamiento de los roles de género en esa época provino de diversos ámbitos. De acuerdo con Rosaura Zapata, directora general de Educación Preescolar, los niños preferían que sus libros tuvieran imágenes de aviadores, soldados y carpinteros y a las niñas les gustaba dibujar, realizar "actividades propias de su sexo" como jugar con muñecas o representar actividades domésticas, como barrer, lavar o planchar. En algunas escuelas las maestras enseñaban a las niñas a planchar con pequeñas planchas eléctricas. ${ }^{77}$ La Iglesia católica también se encargó de reforzar los roles de género en los espacios que tuvo cercanos a la infancia. En dos de sus revistas publicadas en los años sesenta, Pequeña y Piloto, se seguía considerando a las habilidades del cuidado del hogar como un ingrediente clave para la formación de las nińas pequeñas. La revista Pequeña tenía recetas en cada página y recomendaciones para todo tipo de quehaceres domésticos, desde eliminar olores de los cuchillos de cocina hasta colgar cuadros sin dañar las paredes. Para los niños se reiteraron los discursos deportivos que fomentaban la competencia y la cooperación, así como el respeto por la disciplina y la autoridad. ${ }^{78}$ En ese sentido,

${ }^{76}$ Anuncios, El Universal, 1a sección, 16 de diciembre de 1951, 11.

${ }^{77}$ Eileen Mary Ford, Children of the Mexican Miracle: Childhood and Modernity in Mexico City, 1940-1968, Tesis doctoral de la University of Illinois, Urbana-Champaign, 2008, 84-85.

${ }^{78}$ Eileen Mary Ford, Children of the Mexican..., pp.152-157. 
podemos intuir que los juguetes bélicos, dirigidos especialmente a los niños, promovían ideas de virilidad, agresión y fuerza, características que se consideraban propias de la masculinidad.

Si en las escuelas los maestros alentaban a los nińos a participar en actividades específicas de género no resulta sorprendente que el mundo comercial continuara con la idea de la "domesticación femenina” y los "discursos normativos, heredados del siglo XIX, según los cuales las mujeres debían ser principalmente sujetos domésticos"79 $\mathrm{y}$ los hombres debían ir al frente de batalla. Aunque niños y niñas podían compartir juguetes, el mercado insistía en reproducir las relaciones sociales ya existentes. De tal forma, la publicidad que invitaba a acercarse a ese mercado de juguetes contribuyó a desarrollar el papel de niña y futura mujer mexicana como un sujeto hogareño y dedicado a las labores domésticas. No sólo se "comercializó al ama de casa", como analizó Martha Santillán, convirtiéndola en ideal moderno de la "gran ejecutiva del hogar" ${ }^{0}$ sino también se comercializó a la niña.

Los grupos "proinfancia" tanto gubernamentales como privados se vincularon con el mundo del consumo para reproducir los estereotipos de género y entregar a las niñas "muñecas y casas de muñecas, y a los niños pelotas de béisbol, juegos de boliche, cajas de soldados, fusiles, cornetas, tambores" ${ }^{81}$ Para los niños ofrecieron "pistola metálica estilo vaquero", bádminton infantil "idéntico al de papá", herramientas para "carpinterito", y para las niñas "batería de cocina”, graciosas muñecas de organdí, juego de recámara de plástico, "mesita de madera con rueditas para que su niñita sirva su té". Se proclamaba que "ellas verán sus sueños realizados con regalos de El Palacio de Hierro". Los productos para nińas eran muy diversos: vistosos costureros "de mimbre forrado de seda, con accesorios azul o rosa, propio para la nena”, "maquinita de coser importada para hacer los vestidos a las muñecas", "magnífica bolsa para niña”, muñeca con música, bebé imitación piel, té de fina porcelana, "juego de repostería para que su niña se entrene en hacer riquísimos paste-

${ }^{79}$ Martha Santillán, "Discursos de redomesticación femenina durante los procesos modernizadores en México, 1946-1958” en Historia y Grafía, 31, 2008, 103.

${ }^{80}$ Martha Santillán, "Discursos de redomesticación...", p. 123.

${ }^{81}$ Anuncios, Excélsior, 6 de enero de 1956, 4. 
les”, "juego de tres cepillos para las amitas de casa”. Los juguetes para nińas coincidían con los regalos que la publicidad proponía para el día de la madre: electrodomésticos, licuadoras, estufas o planchas eléctricas. En los anuncios se mostraba que, "Santa Claus también se [acordaba] de Papá y Mamá” con una rasuradora para él y una aspiradora y plancha Philips para ella. ${ }^{82}$

Los manuales de cuidado infantil de la época, como el de la médica y psicóloga estadounidense Ruth E. Hartley, enfatizaban que "tanto los niños como las niñas juegan a 'casitas, barren, friegan, visten y desnudan las muñecas y las llevan a 'paseo"” ${ }^{83}$ Hartley había recibido una beca de dos años en el National Institute of Mental Health para analizar la incidencia del juego en la personalidad de los niños. Para esta psicóloga era hasta los cinco años cuando los niños comenzaban a hacer distinciones de género. Es decir, a mediados de los años cuarenta esta autora sostenía que los roles de género eran una construcción social.

El interés de las niñas se concentra, en términos generales, en juegos de muñecas y en las "casas" de éstas. Se precisa una muñeca muy sólida para resistir inmunemente a las prácticas a las que es sometida: se la lava, se la peina y empolva; se la viste, desnuda y mete en cama; se le dan medicinas, se la castiga, etc. En otras palabras, se la somete al mismo proceso a que la propia nińa es sometida por los adultos, especialmente por su madre. [...] Las niñas, a su vez, suelen gozar con las múltiples lanas e hijos de colores que pasan y repasan por un pedazo de tela cualquiera, aunque muchas son las que disfrutan también con los juegos de los niños [...] Saber saltar a la cuerda es indispensable a las niñas, y éstas y los nińos han de saber jugar a la pelota. ${ }^{84}$

En 1952, el doctor Alfredo Ramos Espinosa retomaba esta interpretación, pero le agregaba un componente: "se considera la casa de muñecas como juguete clásico de las nińas. También los niños pueden jugar con ella, también necesitan aprender el encanto de la vida

${ }^{82}$ Anuncios, El Universal, 1a sección, 18 de diciembre de 1951, 6.

${ }^{83}$ Ruth E. Hartley, "Los nińos crecen jugando" en Sidonie Matsner Gruenberg, Los hijos; enciclopedia ilustrada para su crianza y educación, Barcelona, Iberia, 1956, 633.

${ }^{84}$ Ruth E. Hartley, "Los nińos crecen...”, p. 634. 
hogareña. También ellos necesitan jugando, aprender a soñar con un hogar tranquilo y feliz. El hogar no lo forma ella solamente sino ella y él. Si la mujer cuida la casa, el hombre tiene que edificarla. ${ }^{85}$ Así, las casitas y las muñecas servirían para reforzar los roles de género masculinos en los nińos mexicanos. Los juguetes y los discursos en torno a éstos parecieron convenir en que la función del niño era pelear fuera de casa con sus pistolas, tanques y bayonetas y la de la niña, planchar, cocinar y tomar el té.

\section{Breves CONSIDERACIONES FINALES}

Las formas en que los niños utilizaron y se apropiaron de sus juguetes fueron infinitas, tal vez ni siquiera sea posible reconstruirlas en su totalidad, sin embargo, los juegos infantiles de los niños de la década de 1950 se vieron signados no sólo por la imaginación, sino por la publicidad, los objetos culturales (en este caso los juguetes), así como por el contexto social, político y económico e incluso por las relaciones comerciales, económicas y culturales de México con el vecino país del norte. Podría pensarse que los acontecimientos bélicos internacionales de mediados del siglo xx apenas modificaron o incidieron en los hábitos y comportamientos de los niños de la sociedad mexicana. Sin embargo, éstos también participaron de las guerras mundiales y del ambiente militarista a través de un mundo de fantasía mediado por los juguetes. El mercado, sus metralletas, sus tanques y modernos submarinos contendieron no sólo contra los juguetes "tradicionales" mexicanos sino también contra quienes defendían un mundo en el que reinara la paz, la gracia, la nobleza, la ingenuidad y "el ingenio del pueblo mexicano". Por otro lado, los juguetes bélicos fueron utilizados para reproducir discursos de género dominantes en los que la masculinidad se definía desde la valentía, el combate o la agresión al prójimo.

Los juguetes dieron cuenta de las contradicciones sociales, económicas y culturales que vivía México en ese entonces, mostraron otra parte de la complejidad en las relaciones México-Estados Uni-

${ }^{85}$ Alfredo Ramos Espinosa, El cuidado del niño, p. 103. 
dos, dieron cuenta de los avances tecnológicos, de los nuevos materiales y dejaron prueba de los valores, hábitos y comportamientos que los adultos intentaron desarrollar en los niños. En los juguetes y en su publicidad, como hemos mostrado en este artículo, convergieron discursos provenientes de diversas disciplinas y el mundo del juguete lejos de homogeneizar a la infancia mexicana acentuó las diferencias entre clases sociales, mismas que fueron reforzadas por los discursos de los especialistas en la infancia. El plástico y el juguete industrial parecieron coadyuvar en la seguridad y la salud mental y física de los niños promovida por pediatras, psicólogos y pedagogos en las guías de cuidado infantil. Por el contrario, el juguete se alejó de las recomendaciones de los especialistas cuando reprodujo los instrumentos de guerra que utilizaban los adultos en el mundo político. Los discursos alrededor del juguete bélico crearon estereotipos alrededor de los niños de los sectores populares y sus familias. Mientras tanto, los costosos juguetes industriales que se vendían en las jugueterías, dirigidos a los nińos de los sectores medios y altos, fueron promocionados como coadyuvantes en la felicidad y la unión familiar.

La relación de la infancia mexicana con el consumo ha tenido múltiples aristas. En todo caso, este texto es una invitación a que se extiendan las investigaciones sobre este vínculo, relevante para comprender no sólo el mundo de las experiencias infantiles en torno a las producciones culturales en el México del siglo xx sino la historia del consumo en su sentido más amplio.

REFERENCIAS

Hemerografia

Criminalia, 1958

Gaceta médica de México, 1954

El Nacional, 1953-1957

El Porvenir, 1951

El Universal, 1951-1957

Excélsior, 1954-1956 
Guión de acontecimientos nacionales e internacionales, 1957

Hoy, 1952.

Jueves de Excélsior, 1959

La Familia, 1950

Mañana, 1950-1954

\section{BibliografíA}

Alarcón, Alfonso G., El cuidado del niño: los cien mejores consejos que puede recibir una madre acerca de la salud de su niño pequeño, México, Nipios, 1940.

Ariès, Philippe, El niño y la vida familiar en el Antiguo Régimen, México, Taurus, 1998.

Barón Fernández, José, Manual de Puericultura, México, s.e., 1950. Benjamin, Walter, "The Cultural History of Toys" [1928], en Walter Benjamin, Selected Writings, vol. 2, 1927-1934, Cambridge, Belknap Press of Harvard University Press, 1999, 113-116. , Escritos: la literatura infantil, los niños y los jóvenes, Buenos Aires, Nueva Visión, 1989.

Coloquio de Historia de la Educación, Paulí Dávila Balsera y Luis María Naya, La infancia en la historia: espacios y representaciones, Donostia, Erein, 2005.

Cook, Daniel Thomas, The Commodification of Childhood: the Children's Clothing Industry and the Rise of the Child Consumer, Durham, Duke University Press, 2004.

Comte-Sponville, André, Jean Delumeau, Arlette Farge, La historia más bella de la felicidad, Barcelona, Anagrama, 2005.

Cross, Gary S., Kids' Stuff: Toys and the Changing World of American Childhood, Cambridge, Massachusets, Harvard University Press, 2001.

Diccionario Porrúa de historia, biografía y geografía de México, vol. 1, México, Porrúa, 1995,

EsCardó, Florencio, Anatomía de la familia, 2a ed., Buenos Aires, El Ateneo, 1952.

Estados Unidos, Children's Bureau, El niño de uno a seis años, Washington, U.S. Govt. Print. Off., 1947. 
Ford, Eileen Mary, Children of the Mexican Miracle: Childhood and Modernity in Mexico City, 1940-1968, Tesis doctoral de la University of Illinois, Urbana-Champaign, 2008.

Hartley, Ruth E., "Los niños crecen jugando" en Sidonie Matsner Gruenberg, Los hijos; enciclopedia ilustrada para su crianza y educación, Barcelona, Iberia, 1956, 629-638.

Lenroot, Katharine F., ¿Cómo debe cuidarse al niño en su primer año?, México, Novaro, 1958.

Litchfield, Harry Robert y Leon Haskins Dembo, Guía para el cuidado de su hijo, Buenos Aires, Paidós, 1966 [Primera edición en inglés: 1960].

Lipovetsky, Gilles, La felicidad paradójica, Barcelona, Anagrama, 2010.

LoAeza, Soledad, Clases medias y politica en México: la querella escolar, 1959-1963, México, El Colegio de México, 1988.

Manson, Michel, "La historia del juguete: un ámbito inexplorado en la historia de la educación (historiografía y problemática)", en María Esther Aguirre Lora, Rostros históricos de la educación. Miradas, estilos, recuerdos, México, Centro de Estudios Sobre la Universidad, Fondo de Cultura Económica, 2001, 197-220.

Martínez Reina, María del Carmen y Manuel Vélez Cea, "Actitud en nińos y adultos sobre los estereotipos de género en juguetes infantiles", Ciencia Ergo Sum 16, 2009, 137-144.

McMahon, Darrin M., Una historia de la felicidad, México, Taurus, 2006.

Mergen, Bernard, "Made, Bought, and Stolen: Toys and the Culture of Childhood" en Elliott West y Paula Evans Petrik, Small Worlds: Children \& Adolescents in America, 1850-1950, Lawrence, Kansas, University Press of Kansas, 1992, 86-106.

Mraz, John, Nacho López y el fotoperiodismo mexicano en los años cincuenta, México, Océano, 1999.

Pacheco, José Emilio, Las batallas en el desierto, México, Era, 1999. Powdermarker, Florence y Louise Ireland Grimes, Cómo atender y cómo entender al niño, manual para padres y maestros, Buenos Aires, Kapeluz, 1954.

Ramos Espinosa, Alfredo, El cuidado del niño y la moderna psicolo- 
gía, puericultura pedagógica del niño mexicano, México, s.e., 1952.

Ruiz, Ramón Eduardo, México: 1920-1958: el reto de la pobreza y del analfabetismo, México, Fondo de Cultura Económica, 1977.

SÁnCHez Ríos, Feliciano, La puericultura en México, obra de texto de acuerdo con los programas vigentes de la materia, México, Publicaciones Puericultura, 1952.

Santillán, Martha, "Discursos de redomesticación femenina durante los procesos modernizadores en México, 1946-1958” en Historia y Grafía, 31, 2008, 103-132.

Sosenski, Susana, "El niño consumidor: una construcción publicitaria de mediados de siglo xx", en Ariadna Acevedo y Paula López Caballero, coords., Ciudadanos inesperados. Procesos de formación de la ciudadania ayer y hoy, México, Departamento de Investigaciones Educativas, Cinvestav, El Colegio de México (en prensa).

Spock, Benjamin, Tu hijo, Madrid, Daimon, Biblioteca Práctica del Hogar, 1957.

Stekel, Wilhelm, Cartas a una madre, Buenos Aires, Iman, 1959.

Torres, Blanca, Historia de la Revolución Mexicana, 1940-1952.

Hacia la utopía industrial, vol. 21, México, El Colegio de México, 1984.

FECHA DE RECEPCIÓN DEL ARTículo: 20 de junio de 2011

FECHA DE ACEPTACIÓN Y RECEPCIÓN DE LA VERSIÓN FINAL: 17 de agosto de 2011 